\title{
Successful Endoscopic Surgery for L5 Radiculopathy Caused by Far-Lateral Disc Herniation at L5-S1 and L5 Isthmic Grade 2 Spondylolisthesis in a Professional Baseball Player
}

\author{
KAZUTA YAMASHITA, FUMITAKE TEZUKA, HIROAKI MANABE, MASATOSHI MORIMOTO, FUMIO \\ HAYASHI, YOICHIRO TAKATA, TOSHINORI SAKAI, HIROSHI YONEZU, KOSAKU HIGASHINO, \\ TAKASHI CHIKAWA, AKIHIRO NAGAMACHI, KOICHI SAIRYO \\ Department of Orthodontics, Tokushima University, Tokushima, Japan
}

\begin{abstract}
Background: We report the case of a professional baseball player who had severe leg pain due to lumbar lateral disc herniation at L4-5 and isthmic spondylolisthesis at L5 (double crash syndrome). For early recovery to competitive level, we performed minimally invasive endoscopic decompression surgery without fusion. There are few reports to discuss the usefulness of minimally invasive treatment for top athletes.

Methods: A 29-year-old professional baseball player who played catcher was referred to us with a complaint of right leg pain. The previous doctor diagnosed far-lateral disc herniation and Grade 2 isthmic spondylolisthesis and recommended arthrodesis at L5-S1 as treatment for both pathologies. Radiological imaging showed that the right L5 nerve root was impinged by the 2 lumbar disorders, namely, far-lateral disc herniation and a ragged edge around a pars defect. We had taken into account the patient's occupation and his wish to avoid a lengthy sick leave, and we had performed endoscopic decompression surgery during the offseason. The far-lateral disc herniation at L5-S1 was removed under local anesthesia by percutaneous endoscopic discectomy, after which the ragged edge at the pars defect was removed under general anesthesia using a microendoscopic discectomy system. Given that the patient did not have any low back pain, arthrodesis was not considered.

Results: The leg pain resolved after surgery. The following year (2015), the patient resumed playing baseball from the beginning of the season and played in 41 games. In the 2016 season, he played in 71 games without any symptoms. No further slippage was observed at radiological follow up 1 year after the surgery.

Conclusions: Minimally invasive endoscopic surgery is an option for radiculopathy in very active patients who need an early return to their previous level of physical activity.

Endoscopic Minimally Invasive Surgery

Keywords: endoscopic surgery, minimally invasive surgery, spondylolisthesis, lumbar disc herniation, athlete
\end{abstract}

\section{INTRODUCTION}

Lumbar spondylolysis, or a stress fracture at the pars interarticularis, ${ }^{1}$ usually occurs in children and adolescents who are active sports players. ${ }^{2-6}$ When the pars fracture leads to pseudoarthrosis in these young patients, slippage becomes a concern. ${ }^{7,8}$ Spondylolysis and spondylolisthesis are essentially clinically benign conditions in which conservative treatment is effective. ${ }^{2-6}$ However, if the degree of slippage exceeds Grade 2, fusion arthrodesis surgery is sometimes required. ${ }^{9-11}$

Baseball is a very popular sport in Japan. In a literature review, Sakai et $\mathrm{al}^{12}$ reported that about $30 \%$ of professional baseball players had lumbar spondylolysis, which is a very high rate when compared with the rate of about $6 \%$ reported in the general population. ${ }^{13}$ Herein, we describe the case of a professional baseball player who underwent minimally invasive endoscopic decompression surgery for Grade 2 isthmic spondylolisthesis. In the 2 years after the surgery, this patient has been very active without any symptoms. We also discuss the effectiveness of minimally invasive endoscopic surgery in very active professional athletes.

\section{CASE REPORT}

A 29-year-old professional baseball player was referred to our clinic seeking minimally invasive 


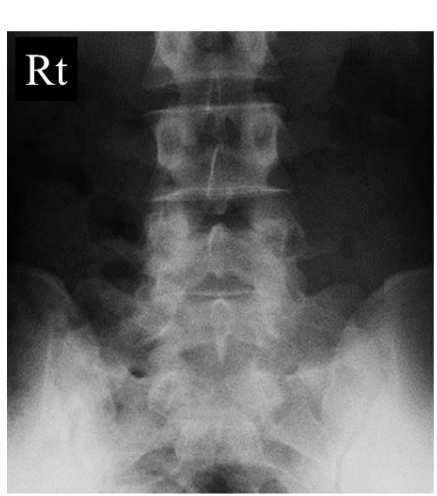

AP view

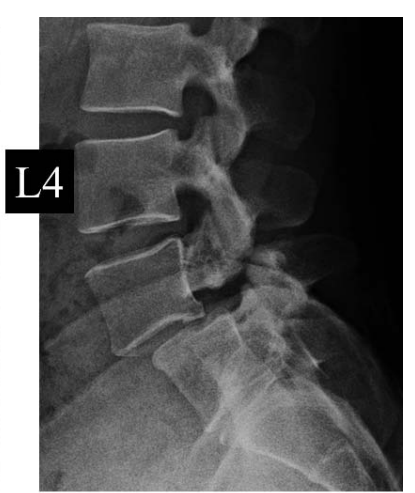

lateral view
Figure 1. Plain radiographs before surgery. The left panel shows an anteroposterior view and the right panel shows a lateral view. Grade 2 isthmic spondylolisthesis of $L 5$ can be seen on the lateral view.

endoscopic surgery for L5 radiculopathy. He had noticed right leg pain during a baseball game, but the pain was not severe, so he continued his sports activities. However, the pain gradually increased, so the team doctor requested magnetic resonance imaging (MRI), computed tomography (CT) scans, and plain radiographs to identify the pathology causing the pain. The radiological findings were of L5 nerve root impingement caused by far-lateral disc herniation at L5-S1 and a ragged edge (ie, a hooklike osteophyte) at an L5 pars defect on the right side. The lesion was found to be Grade 2 isthmic spondylolisthesis. Initially, the plan was for surgical intervention during the upcoming winter offseason. However, given that the patient needed to return to play in the next season, the team doctor decided that a minimally invasive procedure would be the best intervention.

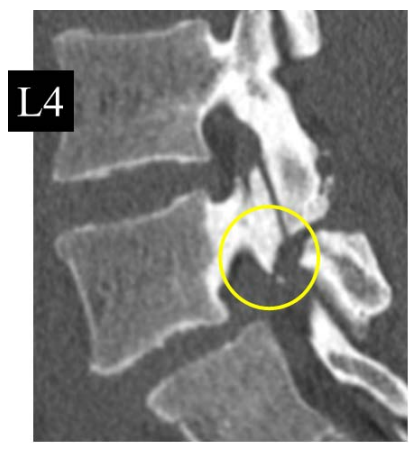

Right para-sagittal

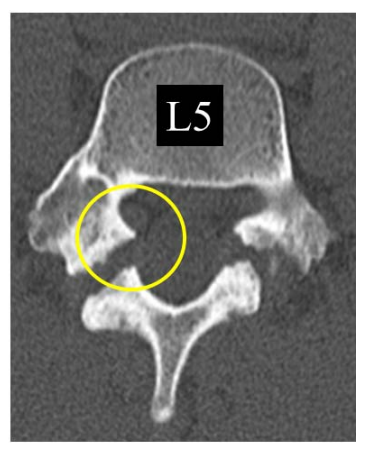

L5 oblique axial
Figure 2. Computed tomography scans before surgery. The left panel shows a right parasagittal view, and the right panel shows an oblique axial view of L5. Circles indicate a right ragged edge at L5.

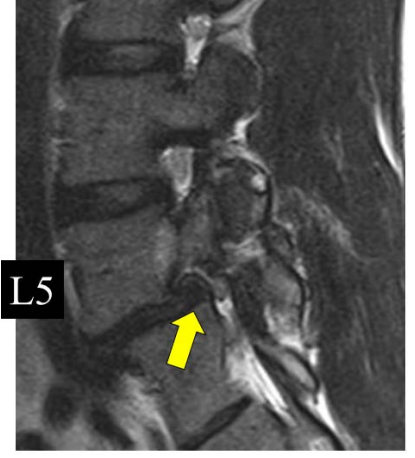

Right para-sagittal

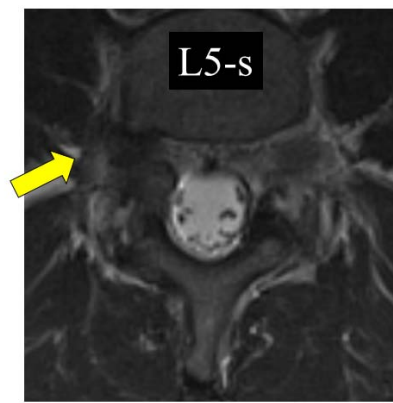

L5 oblique axial
Figure 3. Magnetic resonance images before surgery. The left panel shows a right parasagittal view, and the right panel shows an oblique axial view of L5. Arrows indicate a far-lateral herniated nucleus pulposus on the right side at the level of L5-S1.

The neurological findings at the first visit to our clinic indicated muscle weakness of $4 / 5$ in the right extensor hallucis longus. All deep tendon reflexes were normal, and sensation was intact. A femoral nerve stretch test was normal. However, the straight leg raise test was positive at $70^{\circ}$ on the right side.

The plain radiographs taken before surgery clearly showed Grade 2 isthmic spondylolisthesis (Figure 1). The preoperative sagittal and axial CT scans showed a ragged edge around a pars defect at L5 (indicated by a yellow circle in Figure 2). Farlateral herniated nucleus pulposus (HNP) at a tight L5-S1 level was noted on MRI (indicated by the arrows in Figure 3). After obtaining a radiculogram, a selective nerve root block was performed at L5 on the right (Figure 4). Two levels of nerve root impingement were seen and were attributable to farlateral herniation at L5-S1 (single yellow arrow) and spondylolysis indicated by a ragged edge around the pars defect at L5 (double yellow arrows). The leg pain disappeared temporarily following the

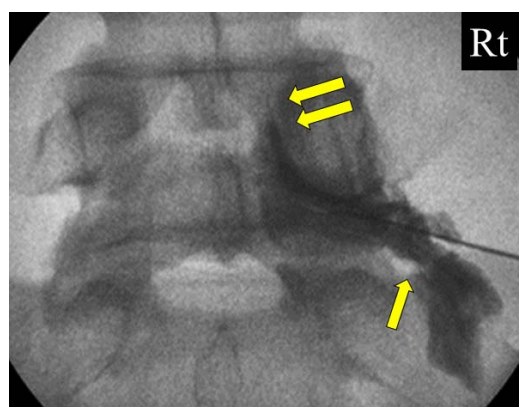

Figure 4. Radiculogram for the right L5 nerve root. Two levels of nerve root impingement are obvious and are attributable to far-lateral herniation at L5-S1 (single yellow arrow) and a ragged edge of a pars defect (spondylolysis) at L5 (double yellow arrows). 

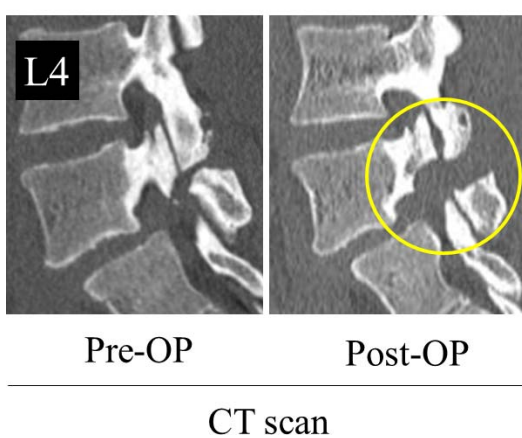

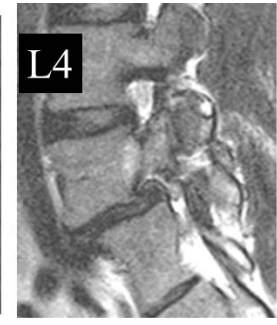

Pre-OP

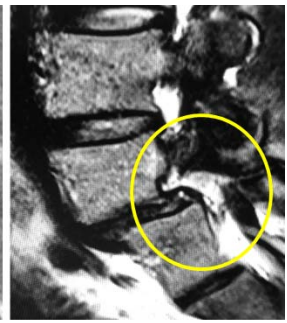

Post-OP

MRI

Figure 5. Magnetic resonance images and computed tomography scans before and after the surgery. The computed tomography scan confirms that the ragged edge was completely removed by the surgery (yellow circle). The magnetic resonance image confirms that the far-lateral herniated nucleus pulposus was also successfully removed endoscopically (yellow circle).

block, which confirmed the pathology of the radiculopathy.

\section{Surgical Intervention}

This patient had 2 pathologies that needed to be addressed. First, we performed percutaneous endoscopic surgery under local anesthesia for the farlateral disc herniation. ${ }^{14}$ With the patient in the prone position, an 8 -mm skin incision was made 5 $\mathrm{cm}$ lateral from the midline. An 8-mm cannula was then inserted through the surface of the disc at L5S1. The far-lateral disc compressing the L5 nerve root was confirmed and removed under endoscopic guidance. Second, the ragged edge was removed using a microendoscopic discectomy (MED) technique under general anesthesia. ${ }^{15}$ A $20-\mathrm{mm}$ skin incision was made followed by insertion of a tubular retractor and stabilization of the pars defect according to the technique proposed by Sairyo et al in 2003. ${ }^{15}$ The ragged edge was exposed on endoscopic views and removed, loosening the tension on the L5 nerve root.

The total operating time was $150 \mathrm{~min}$, and the estimated blood loss was too small to quantify. No complications, such as nerve root injury, dural tear, hematoma, or infection, were encountered during or after the surgery. Figure 5 shows the MRI and CT images before and after surgery. The CT image confirmed complete removal of the ragged edge (yellow circle). The far-lateral HNP had also been successfully removed endoscopically (yellow circle).

\section{Postoperative Course}

Four weeks after surgery, the patient was able to resume stretching and core training of the trunk muscles, and then progressed to jogging and light ball catching. Eight weeks after surgery, he resumed playing baseball. The baseball season started about 3 months later, and in the first year (2015), he played 41 games as catcher. In the second year (2016), he played 71 games without any symptoms. Radiological follow up 1 year after surgery showed no further slippage.

\section{DISCUSSION}

In this case report, we describe use of an endoscopic technique to treat a professional baseball player with Grade 2 isthmic spondylolisthesis at L5. Given his career, an early return to professional sports was the top priority. Therefore, we avoided spinal fusion surgery and opted instead for minimally invasive endoscopic decompression surgery without fusion.

The main symptom in this patient was right leg pain without low back pain. The leg pain was revealed to be L5 radiculopathy. On radiological examinations, we found 2 pathologies, namely, farlateral HNP at L5-S1 and a ragged edge around an L5 pars fracture (Figures 1 through 4). The primary condition was Grade 2 isthmic spondylolisthesis, for which spinal arthrodesis at L5-S1 would be recommended. ${ }^{9-11}$ However, had this patient undergone fusion surgery, he would likely have needed to be on sick leave for at least a year. His position in the team was not secure, so such a long period of recuperation was not a realistic option. To continue his professional career, he needed to return to full sports activity as soon as possible, and this was the most pressing reason for deciding against fusion surgery. 
We opted to perform percutaneous endoscopic surgery under local anesthesia for this patient because it is the least invasive disc surgery. ${ }^{14,16} \mathrm{It}$ can be performed with minimal damage to the paravertebral muscles, so was considered suitable for this professional athlete. ${ }^{14}$ According to the literature, microscopic discectomy is considered to be the gold standard treatment for far-lateral HNP. ${ }^{17}$ Microendoscopic discectomy was established at the end of the last century and is reported to be less invasive than microscopic discectomy. ${ }^{18}$ These 2 techniques, ie, microscopic discectomy and MED, require general anesthesia and a skin incision of approximately 16-30 $\mathrm{mm}$. On the other hand, percutaneous endoscopic discectomy only requires an 8-mm skin incision, so damage to the muscles of the back is minimal, and it can be performed under local anesthesia.

Historically, Gill's laminectomy was the gold standard for decompression in patients with a ragged edge at a pars defect, ${ }^{19,20}$ but it has a risk of additional slippage postoperatively. In 2003, there was a report of removal of a ragged edge using MED. ${ }^{15}$ This technique was minimally invasive and was suggested to preserve the posterior structures. Subsequent research using finite element modeling confirmed no change in the biomechanical environment postoperatively. ${ }^{21}$ For these reasons, we selected endoscope-assisted tubular decompression surgery.

In this patient, 2 different minimally invasive techniques were used successfully to treat 2 pathologies. This baseball player returned to full professional activities in the following season and has been very active in his career in the 2 years since the surgery, although the long-term results of the procedure are unknown.

The biggest concern with regard to the surgical outcome would be progression of slippage following decompression surgery without fusion. ${ }^{20}$ Progression of the slippage, especially in a very active professional athlete, could cause severe back pain and/or recurrent radiculopathy. Sairyo et $\mathrm{al}^{21}$ reported that, unlike with Gill's laminectomy, removal of a ragged edge with preservation of the posterior structures would not change the biomechanical background. However, there is scant information in the literature on the long-term effects of decompression of a ragged edge in very active athletes with Grade 2 isthmic spondylolisthesis. We plan to follow this patient up very carefully for any progression of slippage.

\section{REFERENCES}

1. Wiltse LL, Widell EH Jr, Jackson DW. Fatigue fracture: the basic lesion is inthmic spondylolisthesis. J Bone Joint Surg Am. 1975;57(1):17-22.

2. Sairyo K, Katoh S, Sasa T, et al. Athletes with unilateral spondylolysis are at risk of stress fracture at the contralateral pedicle and pars interarticularis: a clinical and biomechanical study. Am J Sports Med. 2005;33(4):583-590.

3. Sairyo K, Katoh S, Takata Y, et al. MRI signal changes of the pedicle as an indicator for early diagnosis of spondylolysis in children and adolescents: a clinical and biomechanical study. Spine (Phila Pa 1976). 2006;31(2):206-211.

4. Sairyo K, Sakai T, Yasui N. Conservative treatment of lumbar spondylolysis in childhood and adolescence: the radiological signs which predict healing. J Bone Joint Surg Br. 2009;91(2):206-209.

5. Sairyo K, Sakai T, Yasui N, Dezawa A. Conservative treatment for pediatric lumbar spondylolysis to achieve bone healing using a hard brace: what type and how long?: Clinical article. J Neurosurg Spine. 2012;16(6):610-614.

6. Nitta A, Sakai T, Goda Y, et al. Prevalence of symptomatic lumbar spondylolysis in pediatric patients. Orthopedics. 2016;39(3):e434-e437.

7. Ikata T, Miyake R, Katoh S, Morita T, Murase M. Pathogenesis of sports-related spondylolisthesis in adolescents. Radiographic and magnetic resonance imaging study. Am J Sports Med. 1996;24(1):94-98.

8. Sairyo K, Katoh S, Ikata T, Fujii K, Kajiura K, Goel VK. Development of spondylolytic olisthesis in adolescents. Spine $J$. 2001;1(3):171-175.

9. Wenger M, Sapio N, Markwalder TM. Long-term outcome in 132 consecutive patients after posterior internal fixation and fusion for Grade I and II isthmic spondylolisthesis. J Neurosurg Spine. 2005;2(3):289-297.

10. Girardo M, Bettini N, Dema E, Cervellati S. Uninstrumented posterolateral spinal arthrodesis: is it the gold standard technique for I degrees and II degrees grade spondylolisthesis in adolescence? Eur Spine J. 2009;18(Suppl 1):126-132.

11. Nooraie H, Ensafdaran A, Arasteh MM. Surgical management of low-grade lytic spondylolisthesis with C-D instrumentation in adult patients. Arch Orthop Trauma Surg. 1999;119(5-6):337-339.

12. Sakai T, Sairyo K, Suzue N, Kosaka H, Yasui N. Incidence and etiology of lumbar spondylolysis: review of the literature. J Orthop Sci. 2010;15(3):281-288.

13. Sakai T, Sairyo K, Takao S, Nishitani H, Yasui N. Incidence of lumbar spondylolysis in the general population in Japan based on multidetector computed tomography scans from two thousand subjects. Spine (Phila Pa 1976). 2009;34(21):2346-2350.

14. Sairyo K, Egawa H, Matsuura T, et al. State of the art: transforaminal approach for percutaneous endoscopic lumbar discectomy under local anesthesia. J Med Invest. 2014;61(34):217-225.

15. Sairyo K, Katoh S, Sakamaki T, Komatsubara S, Yasui 
N. A new endoscopic technique to decompress lumbar nerve roots affected by spondylolysis. Technical note. J Neurosurg. 2003;98(Suppl 3):290-293.

16. Yeung AT, Tsou PM. Posterolateral endoscopic excision for lumbar disc herniation: surgical technique, outcome, and complications in 307 consecutive cases. Spine (Phila Pa 1976). 2002;27(7):722-731.

17. Overley SC1, McAnany SJ, Andelman S, et al. Return to play in elite athletes after lumbar microdiscectomy: a metaanalysis. Spine (Phila Pa 1976). 2016;41(8):713-718.

18. Foley KT, Smith MM, Rampersaud YR. Microendoscopic approach to far-lateral lumbar disc herniation. Neurosurg Focus. 1999;7(5):e5.

19. Gill GG, Manning JG, White HL. Surgical treatment of spondylolisthesis without spine fusion; excision of the loose lamina with decompression of the nerve roots. $J$ Bone Joint Surg Am. 1955;37-A(3):493-520.

20. Osterman K, Lindholm TS, Laurent LE. Late results of removal of the loose posterior element (Gill's operation) in the treatment of lytic lumbar spondylolisthesis. Clin Orthop Relat Res. 1976;(117):121-128.

21. Sairyo K, Goel VK, Masuda A, Biyani A, Ebraheim N,
Mishiro T, Terai T. Biomechanical rationale of endoscopic decompression for lumbar spondylolysis as an effective minimally invasive procedure - a study based on the finite element analysis. Minim Invasive Neurosurg. 2005;48(2):119122.

Corresponding Author: Kazuta Yamashita, MD, Tokushima University Graduate School of Medicine, 3-18-15 Kuramoto, Tokushima, Tokushima 770-8503, Japan. Phone: +81-88-633-7240; Fax: +81-88-633-0178. Email: kazutayamasita0311@ hotmail.com.

Published 15 October 2018

This manuscript is generously published free of charge by ISASS, the International Society for the Advancement of Spine Surgery. Copyright (C) 2018 ISASS. To see more or order reprints or permissions, see http://ijssurgery.com. 